\title{
The biological effects of tocotrienol on bone: a review on evidence from rodent models
}

\author{
This article was published in the following Dove Press journal: \\ Drug Design, Development and Therapy \\ 8 April 2015 \\ Number of times this article has been viewed
}

\section{Kok-Yong Chin \\ Soelaiman Ima-Nirwana}

Department of Pharmacology, Faculty of Medicine, Universiti Kebangsaan Malaysia Medical Centre, Kuala

Lumpur, Malaysia
Correspondence: Soelaiman Ima-Nirwana Department of Pharmacology, Faculty of Medicine, Universiti Kebangsaan Malaysia Medical Centre, Jalan Yaacob Latif, 56000 Cheras, Kuala Lumpur, Malaysia $\mathrm{Tel}+60391455002$

Fax +60391456633

Email imasoel@ppukm.ukm.edu.my

\begin{abstract}
Osteoporosis causes significant health care and economic burden to society, leading to a relentless search for effective preventive agents. Tocotrienol, a member of the vitamin $\mathrm{E}$ family, has demonstrated promising potential as an osteoporosis-preventing agent. This review summarizes evidence on the effects of tocotrienol on bone in animal models. Techniques used to examine the effects of tocotrienol on bone in animals included bone histomorphometry, X-ray microtomography, dual-energy X-ray absorptiometry, bone turnover markers, bone calcium content, and biomechanical strength. Tocotrienol was shown to improve osteoblast number, bone formation, mineral deposition, and bone microarchitecture in osteopenic rats. It also decreased osteoclast number and bone erosion in the rats. Tocotrienol supplementation resulted in an improvement in bone mineral density, although biomechanical strength was not significantly altered in the rats. The beneficial effects of tocotrienol on bone can be attributed to its role as an antioxidant, anti-inflammatory agent, suppressor of the mevalonate pathway, and modulator of genes favorable to bone formation.
\end{abstract}

Keywords: bone, osteoporosis, tocotrienol, vitamin E

\section{Introduction}

The skeletal system undergoes a constant remodeling process governed by bone cells, ie, osteoblasts for bone formation, osteoclasts for bone resorption, and osteocytes for mechanosensing and mediation of bone remodeling. ${ }^{1}$ An imbalance in bone remodeling, whereby the rate of bone resorption is faster than bone formation, will result in osteoporosis. ${ }^{2}$ Osteoporosis is a metabolic bone disease suffered by both men and women. ${ }^{3}$ The hallmark of osteoporosis is the degeneration of bone density and microarchitecture, leading to bone fragility and fracture. ${ }^{4}$ The prevalence of osteoporosis as reflected by fragility fracture is higher in women than in men, with a $6: 1$ ratio of women to men. ${ }^{3}$ However, the mortality rate post-fracture is higher in men compared to their female counterparts. ${ }^{5,6}$ The major cause of osteoporosis in women is estrogen deficiency due to menopause, while in men it is late-onset testosterone deficiency. ${ }^{7,8}$ Other causes of osteoporosis include prolonged use of glucocorticoid, chronic smoking, alcohol abuse, inflammatory bowel syndrome, celiac disease, immobility, and the use of drugs affecting the skeletal system. ${ }^{9}$ Osteoporosis causes a significant economic burden to society due to loss of productivity and the high cost of treatment. ${ }^{3,10}$

The current therapies for osteoporosis, such as bisphosphonates, teriparatide, and strontium ranelate, are effective in increasing bone mineral density of the patients and reducing fractures, with rare cases of adverse side effects. ${ }^{11}$ They are indicated for patients over 50 years old with a hip or vertebral fracture, osteoporosis, or osteopenia determined by bone mineral density and a high fracture probability. ${ }^{9}$ The commonly prescribed preventive agents, ie, calcium and vitamin $\mathrm{D}$, have been found to be effective 
in preventing fracture among the institutionalized elderly only. According to a meta-analysis, the relative fracture risk for supplemented institutionalized elderly was 0.71 (confidence interval [CI]: 0.57 to 0.89 ) as compared to 0.89 (CI: 0.76 to 1.04 ) in the community-dwelling elderly. ${ }^{12}$ Calcium supplementation alone or in combination with vitamin $\mathrm{D}$ has also been linked to a modest but significant increase in the risk of myocardial infarction (relative risk: 1.24 [CI: 1.07 to 1.45$]$ ) in a meta-analysis involving 28,072 participants. ${ }^{13}$ There are limited alternatives for those who wish to prevent osteoporosis even before onset of bone loss.

Many studies aiming to develop alternative osteoporosispreventing agents using natural products have been performed. One natural product that has received much attention is tocotrienol. Tocotrienol, along with tocopherol, belongs to the lipid-soluble vitamin E family. The molecular structure of tocotrienol consists of a chromanol ring and a long carbon tail with three double bonds, whereas the long carbon tail of tocopherol consists solely of single bonds. ${ }^{14,15}$ Tocotrienol can be further divided into four different homologues, which are alpha-, beta-, gamma-, and delta-tocotrienol, based on the position of side chains on the chromanol ring. ${ }^{14,15}$ Vitamin E from natural sources is usually a mixture of tocotrienols and tocopherols. ${ }^{16}$ The predominant tocotrienol homologue in palm oil is gamma-tocotrienol, ${ }^{17}$ whereas in annatto bean it is delta-tocotrienol. ${ }^{18}$

The antioxidative and anti-inflammatory activities of tocotrienol make it a suitable osteoporosis-preventing agent. Both oxidative stress and inflammation are implicated in the pathogenesis of osteoporosis. ${ }^{19,20}$ Oxidative stress damages osteoblasts and affects their differentiation and survival. ${ }^{21}$ Increased oxidative stress also enhances the signaling of osteoclasts and promotes their differentiation. ${ }^{22}$ Proinflammatory cytokines, such as interleukin-1, interleukin-6, and tumor necrosis factor alpha, promote the differentiation of osteoclasts. ${ }^{23}$ Thus, increased oxidative stress and inflammation will lead to an imbalance in bone remodeling favoring resorption, subsequently resulting in osteoporosis. Tocotrienol exhibits superior antioxidant activity compared to tocopherol due to its uniform distribution in cell membrane, high efficacy in radical recycling, and interaction with lipid radicals. ${ }^{24}$ Tocotrienol also suppresses the expression of proinflammatory cytokines induced by nuclear factor kappalight-chain-enhancer of activated B cells (NFkB). ${ }^{25}$ Hence, it is reasonable to hypothesize that tocotrienol can prevent osteoporosis induced by oxidative stress and inflammation. In fact, several in vitro studies have revealed that tocotrienol homologues suppress the formation of osteoclasts, ${ }^{26,27}$ promote the expression of bone formation genes, ${ }^{28}$ and promote the survival of osteoblasts challenged with oxidative stress. ${ }^{29}$

This review aims to summarize the evidence on the effects of tocotrienol on bone in various rodent models. The effects of tocotrienol on several aspects of bone health, such as bone mineral density, bone microstructure, mineral deposition, and bone strength, are discussed. The review concludes with an overview of the mechanism of action of tocotrienol on bone.

\section{General study design}

Tocotrienol has been tested in various animal models, such as animals that are gonadectomized or treated with glucocorticoid, nicotine, or oxidizing agent (Table 1). The indices of bone health examined include bone microarchitecture determined using histomorphometry and X-ray microtomography, bone turnover markers, bone calcium level, bone mineral density, and biomechanical strength. The treatment period and composition of the tocotrienols used varied from study to study. The general observation was that tocotrienol at the dose of $60 \mathrm{mg} / \mathrm{kg}$ body weight administered orally for 8 weeks was effective in preventing bone loss in rats. A lower dose of tocotrienol ( $30 \mathrm{mg} / \mathrm{kg}$ body weight) had been used, but it took a longer time to show effects. Thus, in the following discussion, tocotrienol administered to the animal was $60 \mathrm{mg} / \mathrm{kg}$ unless mentioned otherwise. Tocotrienol was administered via force-feeding to mimic its consumption as a supplement in humans.

\section{Validity of the animal model}

The gonadectomized young rats generally showed a reduction in bone volume, trabecular number, and trabecular thickness, and an increase in trabecular separation as compared to the sham group after 2 months of surgery. ${ }^{30-32}$ Osteoblast surface, osteoid surface, and osteoid volume were reduced, and osteoclast surface and eroded surface were elevated in the castrated animals compared to the sham group. ${ }^{33,34}$ In an experiment by Ima-Nirwana et al, ${ }^{35}$ bone mineral density of the orchidectomized young rats was significantly reduced as compared to the sham group after 8 months, but Norazlina et $\mathrm{al}^{36}$ failed to demonstrate similar effects of ovariectomy on female rats. There were no significant changes in the bone dynamic parameters between the sham and the gonadectomized animals 2 months post-surgery. ${ }^{30,37,38}$ This might indicate that although bone loss transpired in the castrated growing animals, the changes in bone turnover were brief and undetectable at sacrifice. There were significant changes 


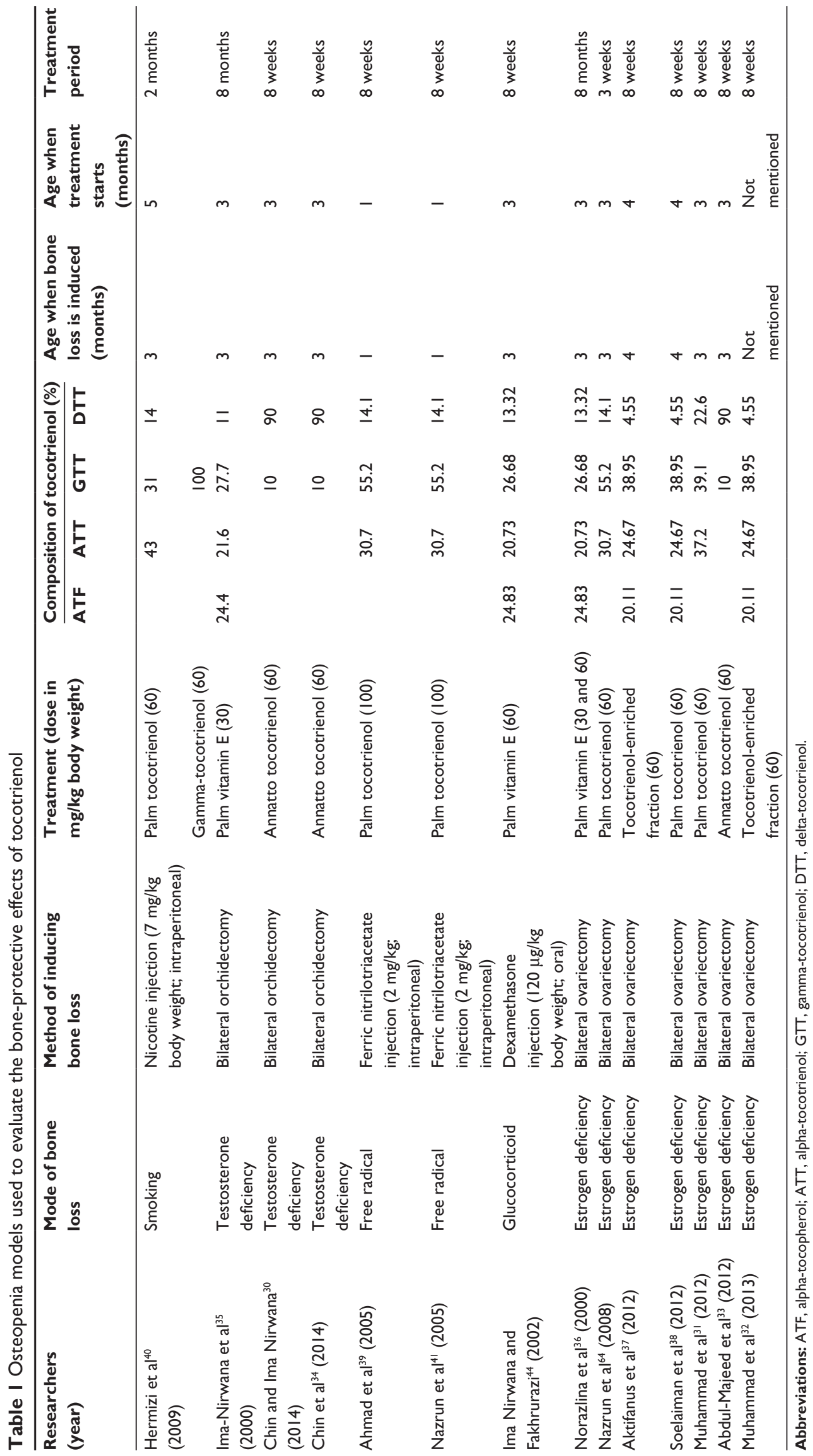


in the bone volume and cellular parameters of the rats treated with nicotine and ferric nitrilotriacetate indicative of bone loss. ${ }^{39-41}$ However, other studies using bone mineral density showed that bone loss did not occur in young ${ }^{42}$ or aged animals ${ }^{43}$ treated with nicotine. The underlying reason for this discrepancy is not known. In the glucocorticoid-induced model, bone loss was not observed because bone mineral density of the rats continued to increase with time. ${ }^{44}$ However, the increase in bone mineral density within the study period was not significant in the glucocorticoid-treated group, whereas it was significant for the other groups. This might indicate an inhibition of growth with glucocorticoid administration. ${ }^{44}$ Nevertheless, other studies have shown that bone mineral density continued to increase with time in young rats (3 months old) treated with glucocorticoid. ${ }^{45}$

With the exception of a few studies, ${ }^{35-37}$ most of the studies had a baseline group. The bone histomorphometric indices of all female rats showed no significant differences between the baseline ( 3 months old) and the sham group (5 months old). ${ }^{31-33,38}$ Although there were no significant changes in structural histomorphometry, significant differences in dynamic and cellular histomorphometry were observed between the baseline ( 3 months old) and the sham group ( 5 months old) in a study using male rats. ${ }^{30}$ Doublelabeled surface, mineral apposition rate, and bone formation rate were higher in the baseline compared to the sham group. This might indicate active bone modeling in the baseline group, which had slowed down after 2 months.

\section{The effects of tocotrienol on bone health \\ The effects of tocotrienol on bone histomorphometry}

Bone histomorphometric examination provides direct information on changes in bone microarchitecture, remodeling/modeling, and cellular properties, which could not otherwise be assessed using bone densitometry and serum bone turnover markers. Bone histomorphometry is guided with computer-aided analysis and stereological technique to provide an accurate depiction of the skeletal changes due to osteoporosis and drug intervention. ${ }^{46,47}$ Nomenclature and definition of indices of bone histomorphometry have been standardized and discussed elsewhere. ${ }^{48}$ Three aspects of bone histomorphometry were given emphasis in previous studies on the effects of tocotrienol on bone, namely bone structural, dynamic, and static/cellular histomorphometry. ${ }^{30,31,33-35,37-41}$ The preferred site of measurement is the trabecular bone at the metaphysis of the distal femur. The trabecular bone is metabolically more active and offers a large surface-to-volume ratio for maximal exposure of stimuli. ${ }^{49}$ Thus, it responds faster to internal or external stimuli compared to the cortical bone.

Indices of bone structural histomorphometry describe the bone amount (bone volume and trabecular number), size (trabecular thickness), and trabecular separation. Two separate studies using an estrogen deficiency model showed that palm tocotrienol preserved trabecular bone structure, especially bone volume and trabecular separation in the ovariectomized rats. ${ }^{31,32}$ In a study by Muhammad et al, the bone-sparing effects of tocotrienol were found to be equivalent to calcium supplementation and estrogen replacement. ${ }^{32}$ Using a testosterone-deficient model, Chin and Ima-Nirwana demonstrated that annatto tocotrienol improved all bone structural indices at the distal femur except trabecular thickness in the orchidectomized rats. ${ }^{30}$ In the same study, bone volume was found to be higher in the testosterone-treated group compared to the tocotrienol-supplemented group, implying that testosterone was more effective than tocotrienol in preventing bone loss due to testosterone deficiency. ${ }^{30}$ Hermizi et al showed that both tocotrienol-rich fraction and gamma-tocotrienol were effective in preserving trabecular bone structure in the nicotine-induced bone loss model. ${ }^{40}$ The effects of tocotrienol on bone structural histomorphometric indices were less pronounced in the ferric nitrilotriacetateinduced osteopenia in rats, whereby only trabecular thickness was maintained in the supplemented group. ${ }^{41}$

Bone dynamic histomorphometry visualizes the mineralization process using fluorescent calcein labeling. ${ }^{50}$ Aktifanus et $\mathrm{al}^{37}$ and Soelaiman et $\mathrm{al}^{38}$ indicated that single-labeled surface was reduced and double-labeled surface was increased in the ovariectomized rats supplemented with tocotrienol. Furthermore, mineral apposition rate and bone formation rate were increased in the supplemented group in both studies. Improvements in mineral apposition rate and bone formation rate were observed in the osteopenic rats supplemented with either tocotrienol-rich fraction or gamma-tocotrienol homologue in the nicotine-induced bone loss model. ${ }^{40}$ Annatto tocotrienol was shown to increase double-labeled surface and reduce single-labeled surface significantly in orchidectomized male rats. ${ }^{30}$ However, mineral apposition rate and bone formation rate were not affected by annatto tocotrienol in the testosterone-deficient model. ${ }^{30}$

Proliferation of bone cells, trabecular erosion, and osteoid deposition were characterized by bone static/cellular histomorphometry indices. ${ }^{47}$ Palm tocotrienol was shown to increase osteoblast surface and decrease osteoclast surface 
in estrogen-deficient rats. ${ }^{31}$ Similarly, Abdul-Majeed et al indicated that osteoblast surface was elevated and osteoclast surface was reduced in ovariectomized rats supplemented with annatto tocotrienol alone or in combination with lowdose lovastatin..$^{33}$ In the same study, they also discovered that both treatment groups had lower eroded surface and higher osteoid surface and volume compared to the unsupplemented ovariectomized group..$^{33}$ In the testosterone deficiency model, annatto tocotrienol increased osteoblast number, osteoid surface, and osteoid volume, and decreased osteoclast and eroded surface in orchidectomized rats. ${ }^{34}$ In the nicotinetreated osteopenic rats, tocotrienol mixture and gammatocotrienol prevented the increase in osteoclast surface and eroded surface. ${ }^{40}$ Ahmad et al demonstrated that, in the ferric nitrilotriacetate-induced bone loss model, palm tocotrienol decreased eroded surface and increased osteoblast number, osteoid surface, and osteoid volume of the supplemented rats compared to the unsupplemented rats. ${ }^{39}$

\section{The effects of tocotrienol on bone microarchitecture assessed by $\mathrm{X}$-ray microtomography}

X-ray microtomography provides a more accurate estimation of bone microarchitecture compared to two-dimensional bone histomorphometry. It provides a high-resolution threedimensional reconstruction of the bone. ${ }^{51}$ A study on the effects of annatto tocotrienol on bone microarchitecture at the proximal tibia in orchidectomized rats was performed by Chin and Ima-Nirwana using X-ray microtomography. ${ }^{30}$ There were trends of improvement in the structural indices such as bone volume, trabecular number, and connectivity density. However, only the difference in trabecular separation reached statistical significance. ${ }^{30}$

\section{The effects of tocotrienol on bone turnover markers}

Bone turnover can also be determined with the circulating level of bone turnover markers, which can be classified into formation and resorption markers. Bone formation markers are proteins secreted by osteoblasts during the fabrication of bone matrix, such as osteocalcin, alkaline phosphatase (ALP), and procollagen type $1 \mathrm{~N}$-terminal propeptide (P1NP). Bone resorption markers are the degradation products of bone matrix, such as carboxyl terminal telopeptide of type 1 collagen crosslinks (CTX-1), pyridinoline crosslinks (PYD), and deoxypyridinoline crosslinks (DYP). Osteoclast-specific proteins like tartrate resistant phosphatase (TRAP) are also used as bone resorption markers. Bone turnover markers are useful for providing continuous monitoring of bone turnover throughout the antiosteoporotic drug intervention. ${ }^{52,53}$

Most of the studies revealed insignificant changes in both bone formation and resorption markers in the ovariectomized rats supplemented with tocotrienol..$^{30,37,38,54}$ In a study by Norazlina et al, supplementation of palm vitamin $\mathrm{E}$ at $30 \mathrm{mg} / \mathrm{kg}$ body weight showed an increase in serum ALP level but a negligible effect on TRAP level in the ovariectomized rats. ${ }^{36}$ This observation could be incidental because supplementation of tocotrienol at a higher dose (60 mg/kg body weight) did not produce a significant effect. ${ }^{36}$ A study by Abdul-Majeed et al indicated a significant lowering of CTX-1 level and an increase in osteocalcin level in the annatto tocotrienol-supplemented rats compared to the unsupplemented ovariectomized rats. ${ }^{33}$ In a testosterone deficiency model, supplementation of annatto tocotrienol did not produce significant changes in either bone formation (osteocalcin and P1NP) or resorption markers (CTX-1 and TRAP5b) in the orchidectomized rats. ${ }^{30,34}$

Norazlina et al administered nicotine $(7 \mathrm{mg} / \mathrm{kg}$ body weight) in male rats for 3 months and initiated tocotrienol treatment in the second and third month. The levels of both osteocalcin and DYP did not differ before (week 0) and after treatment (week 12). ${ }^{54}$ Due to the lack of a proper negative control, the authors could not conclude whether this lack of change was due to the beneficial effect of tocotrienol in suppressing bone turnover or the failure of nicotine in inducing adverse changes in bone turnover. ${ }^{54}$ In a later experiment, Norazlina et al administered nicotine $(7 \mathrm{mg} / \mathrm{kg}$ body weight) in male rats for 2 months to induce bone loss. Immediately after nicotine cessation, they supplemented the rats with tocotrienol for 2 months. ${ }^{55}$ The elevation of PYD and the decrease of osteocalcin due to nicotine administration were averted by tocotrienol supplementation. ${ }^{55}$ Ahmad et al showed that tocotrienol lowered DYP level in the ferric nitrilotriacetate-treated rats compared to the unsupplemented rats. ${ }^{39}$ However, tocotrienol had no effects on the osteocalcin level in this study.

\section{The effects of tocotrienol on bone mineral density}

Dual-energy X-ray absorptiometry is the gold standard in the diagnosis of osteoporosis, as the World Health Organization defines the disease based on bone mineral density. ${ }^{56}$ The recommended skeletal sites for the assessment of bone mineral density are the proximal femur, femoral neck, trochanter, and spine.$^{57}$ Changes in bone histomorphometry precede changes in bone mineral density. In our studies using dual-energy 
X-ray absorptiometry, rats needed to undergo tocotrienol treatment for a longer period of time (9-10 months) as compared to studies employing bone histomorphometry (4-8 weeks) for a significant difference to be observed. ${ }^{35,36,44}$ The ovariectomized rats treated with palm vitamin $\mathrm{E}$ at 30 and $60 \mathrm{mg} / \mathrm{kg}$ body weight had significantly higher bone mineral density at the femur and vertebrae compared to the untreated group. ${ }^{36}$ Similar findings were obtained in the testosterone deficiency and the glucocorticoid bone loss model. ${ }^{35,44}$

\section{The effects of tocotrienol on bone calcium level}

Calcium in the form of hydroxyapatite is the principal inorganic component of bone. ${ }^{58}$ Vitamin D deficiency $(<50 \mathrm{nmol} / \mathrm{L})$ will cause an increase in the parathyroid hormone, which in turn mobilizes calcium from bone to the circulation, subsequently causing osteoporosis. ${ }^{59,60}$ The level of calcium in the bone can be measured using an atomic absorption spectrophotometer. Palm vitamin E was found to restore bone calcium level at the femur and vertebra of orchidectomized and ovariectomized rats. ${ }^{35,36}$ It was also found to preserve bone calcium level in rats receiving dexamethasone. ${ }^{44}$ A study by Muhammad et al showed that tocotrienol did not improve bone calcium level at the vertebrae of ovariectomized rats. ${ }^{32}$ This discrepancy might stem from the fact that the rats were treated in a shorter period of time ( 8 weeks) compared to former studies ${ }^{35,36}$ (9-10 months). Hence, the beneficial effects of tocotrienol on bone calcium level, as in the case of bone mineral density, might take a longer time to manifest.

\section{The effects of tocotrienol on biomechanical strength of bone}

Biomechanical strength of the bone is determined by its material properties and geometric properties (architectural design). ${ }^{61}$ Since tocotrienol has been proved to improve bone mineral density and microarchitecture, it is logical to postulate that it will enhance bone biomechanical strength as well. The biomechanical strength of the bone can be tested using a destructive mechanical test. ${ }^{62}$ A load is applied to a part of the bone to induce strain and fracture, so that its ability to resist deformation (stiffness) and fracture (strength) can be determined. ${ }^{62}$ Shuid et al showed supplementation of gamma-tocotrienol at $60 \mathrm{mg} / \mathrm{kg}$ body weight significantly improved biomechanical strength of the femur in normal male rats. ${ }^{63}$ However, there are limited studies on the effects of tocotrienol on bone biomechanical strength in osteopenia models. In studies by both Nazrun et al and Muhammad et al, palm tocotrienol supplementation did not produce significant improvements in bone biomechanical strength in ovariectomized rats ..$^{32,64}$

\section{Overview on the effects of tocotrienol on bone properties}

The studies discussed so far confirmed that tocotrienol increased osteoblast number and decreased osteoclast number in osteopenic rats. This resulted in an increase in bone matrix deposition and a decrease in eroded surface on the trabecular bone. The increase in osteoblast activity and number led to an elevation of mineralizing surface, mineral apposition rate, and bone formation rate. Thus, bone calcium content was raised. Increased bone formation and decreased bone resorption brought about an accumulation of bone volume and a reduction in bone porosity, as shown in structural histomorphometry. The improved material content (calcium) and microarchitecture should have subsequently preserved the biomechanical strength of the bone in the animal, but this might take a longer time to manifest. Thus, bone health was preserved in the tocotrienol-supplemented group (Figure 1). The effects of tocotrienol on bone histomorphometry, bone mineral density, and bone calcium content are summarized in Table 2.

\section{The mechanism of action of tocotrienol Antioxidant activity of tocotrienol}

Clinical and experimental studies have demonstrated that oxidative stress is implicated in the development of osteoporosis. ${ }^{65,66}$ An increase in oxidative stress leads to decreased differentiation and survival of osteoblasts, ${ }^{67}$ and also increased differentiation of osteoclasts and bone resorption activity, ${ }^{68}$ thus impairing the skeletal system.

Maniam et al showed that supplementation of palm tocotrienol at $100 \mathrm{mg} / \mathrm{kg}$ body weight reduced malondialdehyde, a product of lipid peroxidation, and increased glutathione peroxidase activity, an antioxidant enzyme in the bone of normal male rats. ${ }^{69}$ Nazrun et al indicated that the ovariectomized rats treated with palm tocotrienol showed increased erythrocyte superoxide dismutase and plasma glutathione peroxidase activities and lower malondialdehyde level. ${ }^{64}$ These in vivo studies showed that supplementation of tocotrienol reduced oxidative stress products and antioxidant enzyme activities, subsequently decreasing oxidative stress. In an in vitro study, Nizar et al showed that gamma-tocotrienol homologue decreased oxidative damage on primary osteoblast culture. ${ }^{29} \mathrm{~A}$ further study indicated that tocotrienol achieved 


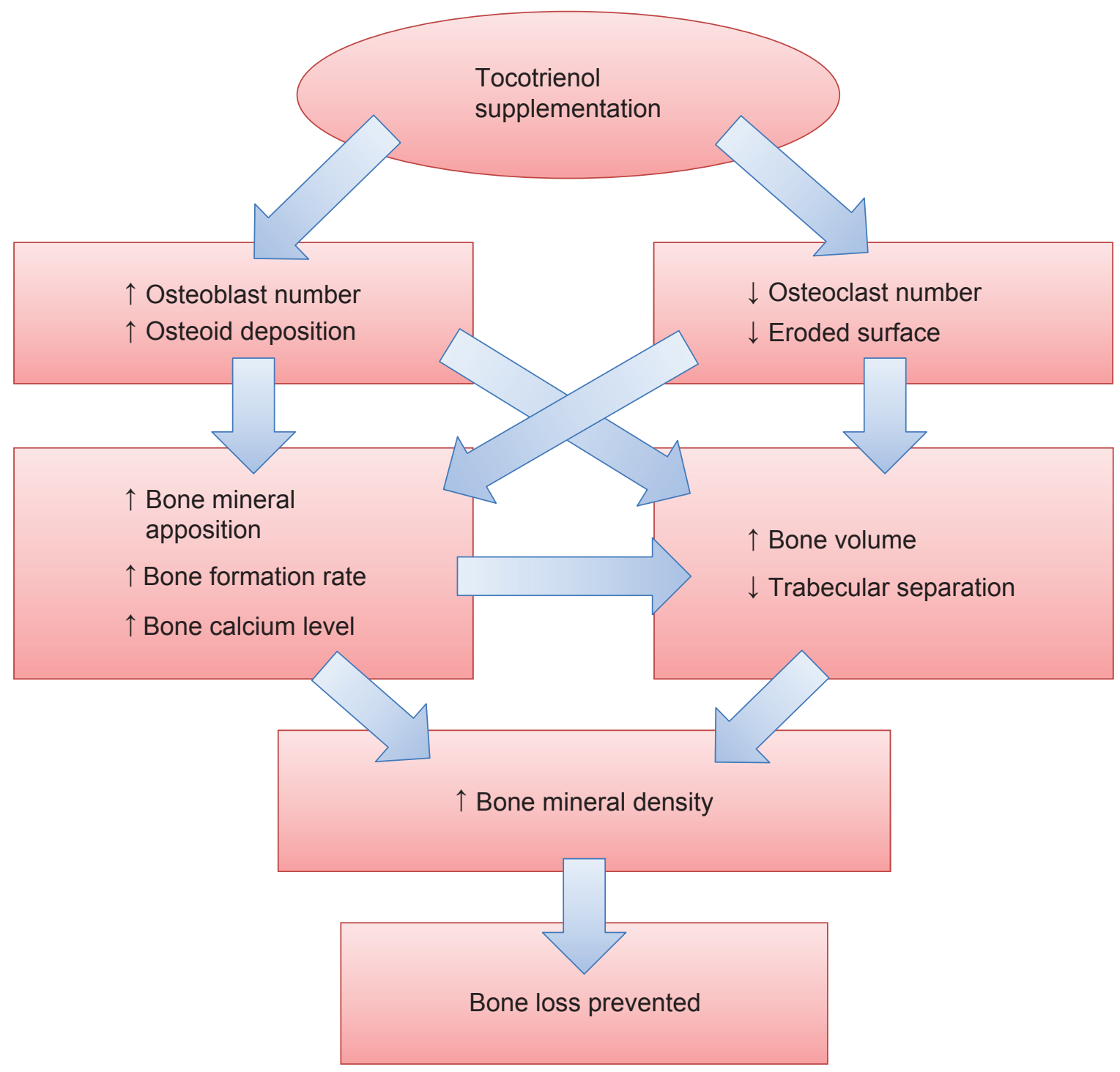

Figure I The effects of tocotrienol on bone.

Notes: $\uparrow$, increases; $\downarrow$, decreases.

its protective effects by preserving the antioxidant enzyme activities in osteoblasts challenged with oxidative stress. ${ }^{70}$

\section{The effects of tocotrienol on the mevalonate pathway}

The mevalonate pathway regulates osteoblastogenesis and osteoclastogenesis through prenylation of small guanosine triphosphate-binding proteins (GTPases), whereby activation of GTPase enhances bone loss. ${ }^{71}$ Similar to statins, tocotrienol can suppress the mevalonate pathway as indicated in a previous study on the hypocholesterolemic effects of tocotrienol. ${ }^{72}$ Tocotrienol achieves this effect by downregulating the activity of hydroxy-methyl-glutaryl-coenzyme A (HMG-CoA) reductase, a key enzyme involved in cholesterol synthesis. ${ }^{73}$
A recent study by Deng et al found that gamma-tocotrienol (100 mg/kg body weight, subcutaneous injection, once monthly for 3 months) improved bone mineral density, bone microarchitecture determined using X-ray microtomography, and bone static and dynamic histomorphometry in the ovariectomized mice. ${ }^{74}$ These effects were brought about by an increased gene expression of bone formation transcription factors (Runx2 and Osterix) and osteoprotegerin, and a decreased expression of gene coding for RANKL in the supplemented mice. ${ }^{74}$ Daily supplementation of mevalonate in the tocotrienol-treated ovariectomized mice reverted these beneficial changes. ${ }^{74}$ This implies that the bone-protective effects of tocotrienol were mediated through the mevalonate pathway. In another study by Abdul-Majeed et al, the combination of tocotrienol together with statins 


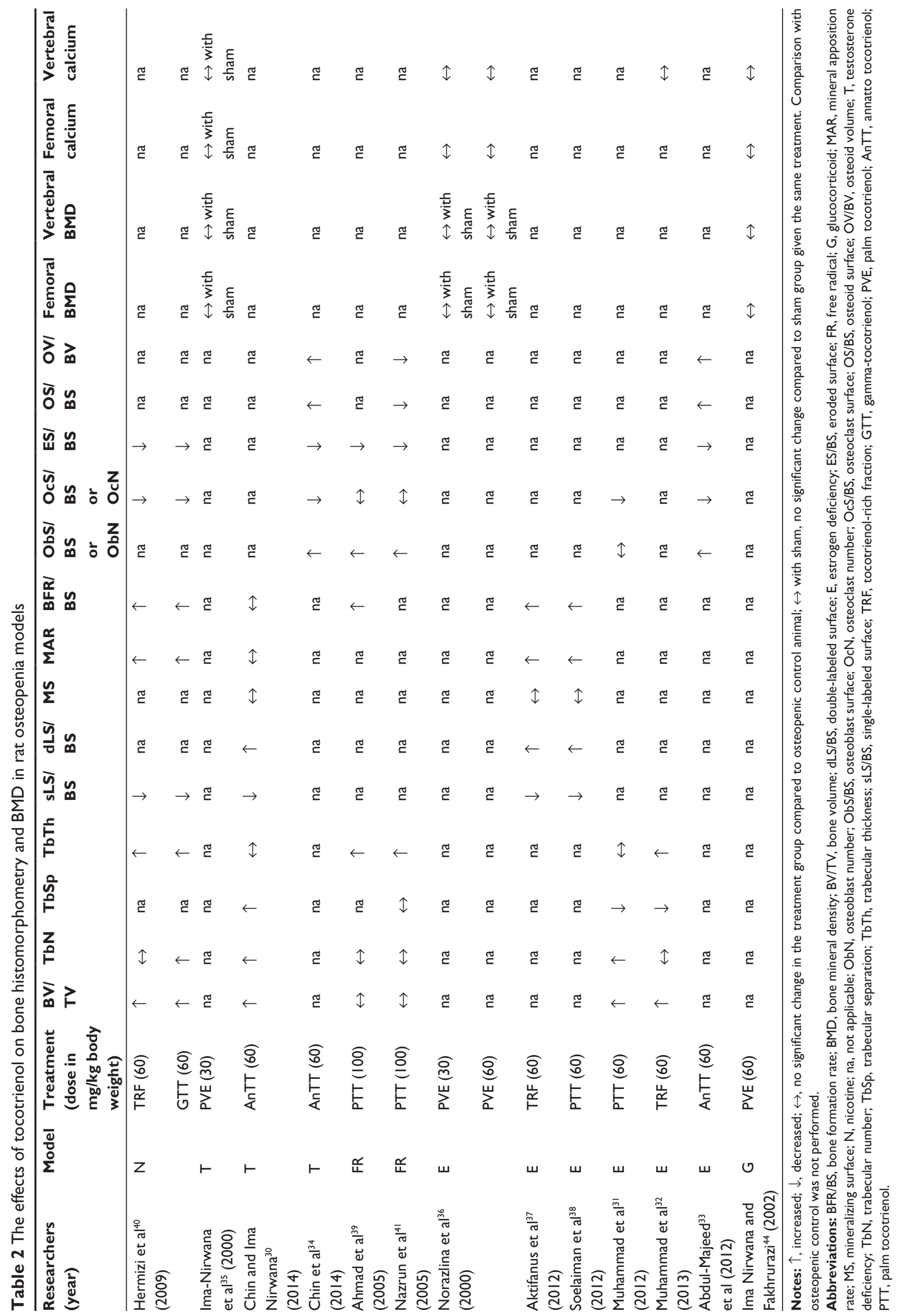


enhanced the effects of tocotrienol in improving bone static histomorphometry and remodeling markers in the ovariectomized rats. ${ }^{33}$ However, there was no confirmation as to whether this effect was produced by the mevalonate pathway per se or by other pathways as well.

\section{The anti-inflammatory effects of tocotrienol}

Proinflammatory cytokines such as interleukin-1, interleukin-6, and tumor necrosis factor alpha are important mediators of bone resorption. ${ }^{23}$ They are also implicated in the pathogenesis of postmenopausal osteoporosis. ${ }^{75}$ Previous studies showed that tocotrienol could prevent ferric nitrilotriacetate- or nicotine-induced elevation of proinflammatory cytokines such as interleukin-1 and interleukin-6 and concurrently preserve the bone health of rats. ${ }^{39,54,55}$ In an in vitro study, Ha et al demonstrated that alpha-tocotrienol could suppress the formation of osteoclasts from co-culture of bone marrow macrophages and osteoblasts induced by interleukin-1 or vitamin $\mathrm{D}$ and prostaglandin $\mathrm{E}_{2} \cdot{ }^{22}$ Concurrently, it was observed that RANKL production by osteoblasts was suppressed and RANKL signaling in the osteoclasts was disrupted. ${ }^{22}$

\section{Gene-modulating effects of tocotrienol}

Differentiation and activity of osteoblasts and osteoclasts are governed by a cascade of genes. ${ }^{76,77}$ Abukhadir et al showed that supplementation of palm vitamin E significantly enhanced the gene expression of Runx2, Osterix, and bone morphogenetic protein-2 in a nicotine cessation osteopenia model. ${ }^{78}$ Chin and Ima-Nirwana showed that annatto tocotrienol could enhance the expression of genes related to bone formation and osteoblast activity such as alkaline phosphatase, beta-catenin, collagen type I alpha 1, and osteopontin. ${ }^{30}$ Gene expression of RANKL was also decreased in the supplemented group. ${ }^{30}$ However, annatto tocotrienol did not affect bone resorption genes in the supplemented rats. ${ }^{30}$

A detailed description of the possible bone-protective mechanism of tocotrienol has been published elsewhere. ${ }^{79}$

\section{The difference in the effects on bone between tocotrienol and alpha-tocopherol}

While most studies revealed beneficial effects of tocotrienol on bone, the effects of alpha-tocopherol supplementation on bone in animals are heterogenous. ${ }^{80}$ Some studies revealed beneficial effects of alpha-tocopherol on bone while others did not. ${ }^{81,82}$ Several studies showed that high-dose alpha-tocopherol supplementation might exert negative effects on bone in normal animals but was protective in stressed animals. ${ }^{83,84}$ A study by Fujita et al showed that there was increased bone resorption in mice fed with high-dose alpha-tocopherol, probably due to increased differentiation of osteoclasts. ${ }^{85}$ However, this study could not be replicated successfully by other researchers. ${ }^{86}$ When alpha-tocopherol and tocotrienol were compared, most studies showed that the effects of the former was either lesser to $0^{40,87}$ or on par with tocotrienol in protecting bone in rats. ${ }^{31,36}$ The effects of alpha-tocopherols on bone have been summarized previously in a review. ${ }^{80}$

\section{The safety of tocotrienol}

Few studies have been performed to assess the safety of tocotrienol. Ima-Nirwana et al showed that treatment with palm tocotrienol at the doses of 500 and $1,000 \mathrm{mg} / \mathrm{kg}$ body weight (oral) increased the bleeding and clotting time of mice in subacute (14 days treatment) and subchronic (42 days treatment) studies. ${ }^{88}$ After conversion, ${ }^{89}$ these are equivalent to 250 and $500 \mathrm{mg} / \mathrm{kg}$ body weight in rats. In another study in which rats were fed with palm tocotrienol for 13 weeks, Nakamura et al observed some changes in hematological and serum enzyme biochemical indices and organ histology. ${ }^{90}$ They concluded that the no-observed-adverse-effect level was $120 \mathrm{mg} / \mathrm{kg}$ body weight for male rats and $130 \mathrm{mg} / \mathrm{kg}$ body weight for female rats. ${ }^{90}$

According to the existing toxicological reports, ${ }^{88,89}$ the therapeutic index for tocotrienol is relatively low for a noncritical agent. There is a two- to fivefold difference between the effective dose and the toxic dose. The toxicological profile of tocotrienol is not as well established as that of alpha-tocopherol, thus more studies are needed. The available evidence shows that it may lower platelet count and prolong bleeding and clotting time..$^{88,90}$ This suggests that it may contraindicate with anticoagulants like warfarin. Apart from that, the pharmacokinetics and disposition of tocotrienol in skeletal tissue is not known. Previous studies revealed that the bioavailability of tocotrienol is relatively low compared to alpha-tocopherol due to the selective binding of tocopherol transport protein with the latter. $^{91,92}$ This may be the reason a higher dose of tocotrienol is needed to achieve its bone-protective effects.

\section{Limitations}

Several limitations should be considered when interpreting the studies presented in the current review. Significant publication bias was noted during the literature search, whereby a majority of the studies on the effects of tocotrienol on bone were published by one research group. While many other researchers also study the effects of vitamin $\mathrm{E}$ on bone, most 


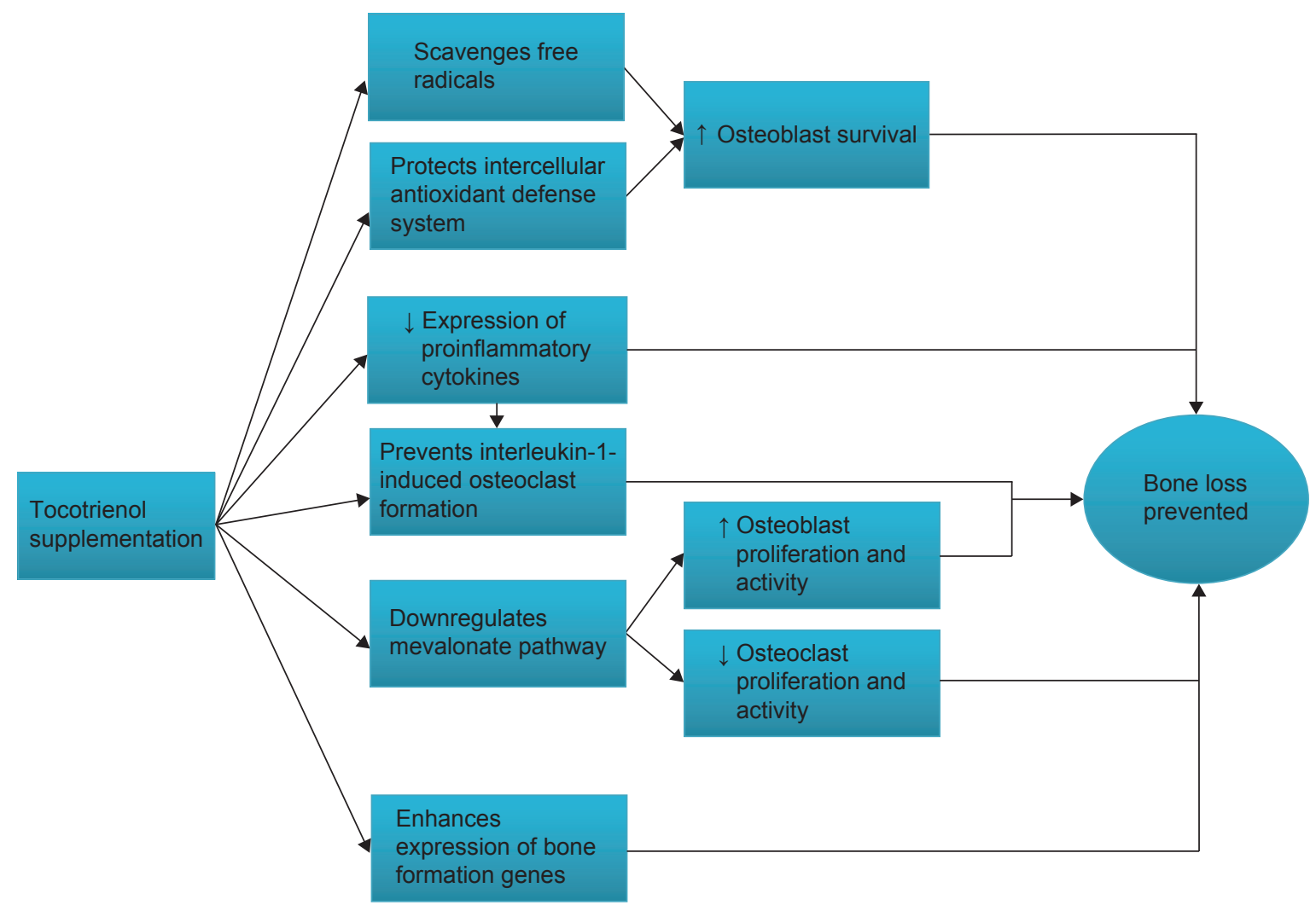

Figure 2 The bone-protective mechanism of tocotrienol.

Notes: $\uparrow$, increases; $\downarrow$, decreases.

of them focus on alpha-tocopherol, ${ }^{83,84}$ which is the predominant vitamin $\mathrm{E}$ homologue in our body and in nature. ${ }^{14}$

\section{Conclusion}

The studies on tocotrienol have confirmed that it possesses promising bone-protective effects in various rat models subjected to estrogen deficiency, testosterone deficiency, glucocorticoid, nicotine, and free radicals. Tocotrienol increases osteoblast number, mineral deposition, and bone formation activity and decreases osteoclast number, erosion on bone, and bone resorption activity, thus preventing the degeneration of bone mineral density and bone microarchitecture in osteopenic animals. These effects could be attributed to the antioxidative, anti-inflammatory, genemodulating activities of tocotrienol. Tocotrienol may also suppress the mevalonate pathway and prevent the activation of GTPase to achieve its bone-protective effects (Figure 2). More studies may be needed to establish the safety profile of tocotrienol. There is also a need to study the effects of tocotrienol in the aged animal model. The data obtained will serve as a basis for future clinical trials to validate the protective effects of tocotrienol in the elderly who are at risk for osteoporosis.

\section{Acknowledgments}

We thank Universiti Kebangsaan Malaysia for providing the grant LAUREATE-2013-003. We also thank Ms Tay Shu Shen for proofreading the manuscript.

\section{Disclosure}

The authors report no conflicts of interest in this work.

\section{References}

1. Jilka RL. Biology of the basic multicellular unit and the pathophysiology of osteoporosis. Med Pediatr Oncol. 2003;41(3):182-185.

2. Feng X, McDonald JM. Disorders of bone remodeling. Annu Rev Pathol. 2011;6:121-145.

3. Johnell O, Kanis JA. An estimate of the worldwide prevalence and disability associated with osteoporotic fractures. Osteoporos Int. 2006;17(12):1726-1733.

4. Kanis JA, Melton LJ 3rd, Christiansen C, Johnston CC, Khaltaev N. The diagnosis of osteoporosis. J Bone Miner Res. 1994;9(8):1137-1141.

5. Koh GC, Tai BC, Ang LW, Heng D, Yuan JM, Koh WP. All-cause and cause-specific mortality after hip fracture among Chinese women and men: the Singapore Chinese Health Study. Osteoporos Int. 2013;24(7): 1981-1989.

6. Kannegaard PN, van der Mark S, Eiken P, Abrahamsen B. Excess mortality in men compared with women following a hip fracture. National analysis of comedications, comorbidity and survival. Age Ageing. 2010; 39(2):203-209.

7. Riggs BL, Khosla S, Melton LJ 3rd. Sex steroids and the construction and conservation of the adult skeleton. Endocr Rev. 2002;23(3):279-302. 
8. Chin KY, Ima-Nirwana S. Sex steroids and bone health status in men. Int J Endocrinol. 2012;2012:208719.

9. National Osteoporosis Foundation. Clinician's Guide to Prevention and Treatment of Osteoporosis. Washington, DC: National Osteoporosis Foundation; 2010. Available from: http://nof.org/files/nof/public/ content/file/344/upload/159.pdf. Accessed March 24, 2015.

10. Burge R, Dawson-Hughes B, Solomon DH, Wong JB, King A, Tosteson A. Incidence and economic burden of osteoporosis-related fractures in the United States, 2005-2025. J Bone Miner Res. 2007;22(3): 465-475.

11. Hough FS, Brown SL, Cassim B, et al; National Osteoporosis Foundation of South Africa. The safety of osteoporosis medication. S Afr Med J. 2014;104(4):279-282.

12. Chung M, Lee J, Terasawa T, Lau J, Trikalinos TA. Vitamin D with or without calcium supplementation for prevention of cancer and fractures: an updated meta-analysis for the U.S. Preventive Services Task Force. Ann Intern Med. 2011;155(12):827-838.

13. Bolland MJ, Grey A, Avenell A, Gamble GD, Reid IR. Calcium supplements with or without vitamin D and risk of cardiovascular events: reanalysis of the Women's Health Initiative limited access dataset and meta-analysis. BMJ. 2011;342:d2040.

14. Aggarwal B, Sundaram C, Prasad S, Kannappan R. Tocotrienols, the vitamin $\mathrm{E}$ of the 21 st century: its potential against cancer and other chronic diseases. Biochem Pharmacol. 2010;80(11):1613-1631.

15. Colombo ML. An update on vitamin E, tocopherol and tocotrienolperspectives. Molecules. 2010;15(4):2103-2113.

16. Chun J, Lee J, Ye L, Exler J, Eitenmiller RR. Tocopherol and tocotrienol contents of raw and processed fruits and vegetables in the United States diet. J Food Compost Anal. 2006;19(2-3):196-204.

17. Ng MH, Choo YM, Ma AN, Chuah CH, Hashim MA. Separation of vitamin $\mathrm{E}$ (tocopherol, tocotrienol, and tocomonoenol) in palm oil. Lipids. 2004;39(10):1031-1035.

18. Frega N, Mozzon M, Bocci F. Identification and estimation of tocotrienols in the annatto lipid fraction by gas chromatography-mass spectrometry. J Am Oil Chem Soc. 1998;75(12):1723-1727.

19. Ginaldi L, Di Benedetto MC, De Martinis M. Osteoporosis, inflammation and ageing. Immun Ageing. 2005;2:14.

20. Manolagas SC. From estrogen-centric to aging and oxidative stress: a revised perspective of the pathogenesis of osteoporosis. Endocr Rev. 2010;31(3):266-300.

21. Fatokun AA, Stone TW, Smith RA. Responses of differentiated MC3T3-E1 osteoblast-like cells to reactive oxygen species. Eur $J$ Pharmacol. 2008;587(1-3):35-41.

22. Ha H, Kwak HB, Lee SW, et al. Reactive oxygen species mediate RANK signaling in osteoclasts. Exp Cell Res. 2004;301(2):119-127.

23. McLean RR. Proinflammatory cytokines and osteoporosis. Curr Osteoporos Rep. 2009;7(4):134-139.

24. Serbinova E, Kagan V, Han D, Packer L. Free radical recycling and intramembrane mobility in the antioxidant properties of alphatocopherol and alpha-tocotrienol. Free Radic Biol Med. 1991;10(5): 263-275.

25. Kaileh M, Sen R. Role of NF-kappaB in the anti-inflammatory effects of tocotrienols. J Am Coll Nutr. 2010;29(3 Suppl):334S-339S.

26. Brooks R, Kalia P, Ireland DC, Beeton C, Rushton N. Direct inhibition of osteoclast formation and activity by the vitamin $\mathrm{E}$ isomer gammatocotrienol. Int J Vitam Nutr Res. 2011;81(6):358-367.

27. Ha H, Lee JH, Kim HN, Lee ZH. $\alpha$-Tocotrienol inhibits osteoclastic bone resorption by suppressing RANKL expression and signaling and bone resorbing activity. Biochem Biophys Res Commun. 2011;406(4): 546-551.

28. Ahn KH, Jung HK, Jung SE, et al. Microarray analysis of gene expression during differentiation of human mesenchymal stem cells treated with vitamin E in vitro into osteoblasts. Korean Journal of Bone Metabolism. 2011;18(1):23-32.

29. Nizar AM, Nazrun AS, Norazlina M, Norliza M, Ima Nirwana S. Low dose of tocotrienols protects osteoblasts against oxidative stress. Clin Ter. 2011;162(6):533-538.
30. Chin KY, Ima Nirwana S. Effects of annatto-derived tocotrienol supplementation in osteoporosis induced by testosterone deficiency in rats. Clin Interv Aging. 2014;9:1247-1259.

31. Muhammad N, Luke DA, Shuid AN, Mohamed N, Soelaiman IN. Two different isomers of vitamin e prevent bone loss in postmenopausal osteoporosis rat model. Evid Based Complement Alternat Med. 2012;2012:161527.

32. Muhammad N, Razali S, Shuid AN, Mohamed N, Soelaiman IN. Membandingkan kesan antara fraksi-kaya tokotrienol, kalsium dan estrogen terhadap metabolisme tulang tikus terovariektomi. Sains Malaysiana. 2013;42(11):1591-1597. Malay.

33. Abdul-Majeed S, Mohamed N, Soelaiman IN. Effects of tocotrienol and lovastatin combination on osteoblast and osteoclast activity in estrogen-deficient osteoporosis. Evid Based Complement Alternat Med. 2012;2012:960742.

34. Chin KY, Abdul-Majeed S, Fozi NF, Ima-Nirwana S. Annatto tocotrienol improves indices of bone static histomorphometry in osteoporosis due to testosterone deficiency in rats. Nutrients. 2014;6(11): 4974-4983.

35. Ima-Nirwana S, Kiftiah A, Zainal AG, Norazlina M, Gapor MT, Khalid BAK. Palm vitamin E prevents osteoporosis in orchidectomized growing male rats. Natural Product Sciences. 2000;6(4):155-160.

36. Norazlina M, Ima-Nirwana S, Gapor MT, Khalid BA. Palm vitamin E is comparable to alpha-tocopherol in maintaining bone mineral density in ovariectomised female rats. Exp Clin Endocrinol Diabetes. 2000;108:305-310.

37. Aktifanus AT, Shuid AN, Rashid NH, et al. Comparison of the effects of tocotrienol and estrogen on the bone markers and dynamic changes in postmenopausal osteoporosis rat model. Asian J Anim Vet Adv. 2012;7(3):225-234.

38. Soelaiman IN, Ming W, Abu Bakar R, et al. Palm tocotrienol supplementation enhanced bone formation in oestrogen-deficient rats. Int J Endocrinol. 2012;2012:532862.

39. Ahmad NS, Khalid BA, Luke DA, Ima Nirwana S. Tocotrienol offers better protection than tocopherol from free radical-induced damage of rat bone. Clin Exp Pharmacol Physiol. 2005;32(9):761-770.

40. Hermizi H, Faizah O, Ima-Nirwana S, Ahmad Nazrun S, Norazlina M. Beneficial effects of tocotrienol and tocopherol on bone histomorphometric parameters in sprague-dawley male rats after nicotine cessation. Calcif Tissue Int. 2009;84(1):65-74.

41. Khalid BAK, Luke DA, Ima-Nirwana S, Nazrun AS. Vitamin E protects from free-radical damage on femur of rats treated with ferric nitrilotriacetate. Curr Top Pharmacol. 2005;9(2):107-115.

42. Turan V, Mizrak S, Yurekli B, Yilmaz C, Ercan G. The effect of long-term nicotine exposure on bone mineral density and oxidative stress in female Swiss Albino rats. Arch Gynecol Obstet. 2013;287(2):281-287.

43. Iwaniec UT, Fung YK, Akhter MP, et al. Effects of nicotine on bone mass, turnover, and strength in adult female rats. Calcif Tissue Int. 2001;68(6):358-364.

44. Ima Nirwana S, Fakhrurazi H. Palm vitamin E protects bone against dexamethasone-induced osteoporosis in male rats. Med J Malaysia. 2002;57(2):136-144.

45. Ogoshi T, Hagino H, Fukata S, Tanishima S, Okano T, Teshima R. Influence of glucocorticoid on bone in 3-, 6-, and 12-month-old rats as determined by bone mass and histomorphometry. Mod Rheumatol. 2008;18(6):552-561.

46. Vedi S, Compston J. Bone histomorphometry. Methods Mol Med. 2003;80:283-298.

47. Kulak CA, Dempster DW. Bone histomorphometry: a concise review for endocrinologists and clinicians. Arq Bras Endocrinol Metabol. 2010;54:87-98.

48. Dempster DW, Compston JE, Drezner MK, et al. Standardized nomenclature, symbols, and units for bone histomorphometry: a 2012 update of the report of the ASBMR Histomorphometry Nomenclature Committee. J Bone Miner Res. 2013;28(1):2-17.

49. Jacobs CR. The mechanobiology of cancellous bone structural adaptation. J Rehabil Res Dev. 2000;37(2):209-216. 
50. Erben R. Bone-labeling techniques. In: An YH, Martin KL, editors. Handbook of Histology Methods for Bone and Cartilage. Totowa, NJ: Humana Press; 2003:99-117.

51. Effendy NM, Khamis MF, Shuid AN. Micro-CT assessments of potential anti-osteoporotic agents. Curr Drug Targets. 2013;14(13): $1542-1551$.

52. Naylor K, Eastell R. Bone turnover markers: use in osteoporosis. Nat Rev Rheumatol. 2012;8(7):379-389.

53. Wheater G, Elshahaly M, Tuck SP, Datta HK, van Laar JM. The clinical utility of bone marker measurements in osteoporosis. J Transl Med. 2013;11:201.

54. Norazlina M, Lee PL, Lukman HI, Nazrun AS, Ima-Nirwana S. Effects of vitamin E supplementation on bone metabolism in nicotine-treated rats. Singapore Med J. 2007;48(3):195-199.

55. Norazlina M, Hermizi H, Faizah O, Nazrun AS, Norliza M, Ima-Nirwana S. Vitamin E reversed nicotine-induced toxic effects on bone biochemical markers in male rats. Arch Med Sci. 2010;6(4): 505-512.

56. World Health Organization. Assessment of Fracture Risk and its Application to Screening for Postmenopausal Osteoporosis: Report of a World Health Organization Study Group. Geneva: World Health Organization; 1994. Available from: http://apps.who.int/iris/ bitstream/10665/39142/1/WHO_TRS_843_eng.pdf?ua=1. Accessed March 24, 2015.

57. Hans D, Downs RW Jr, Duboeuf F, et al; International Society for Clinical Densitometry. Skeletal sites for osteoporosis diagnosis: the 2005 ISCD Official Positions. J Clin Densitom. 2006;9(1):15-21.

58. Legros R, Balmain N, Bonel G. Age-related changes in mineral of rat and bovine cortical bone. Calcif Tissue Int. 1987;41(3):137-144.

59. Saliba W, Barnett O, Rennert HS, Lavi I, Rennert G. The relationship between serum 25(OH)D and parathyroid hormone levels. Am J Med. 2011;124(12):1165-1170.

60. Lips P, Duong T, Oleksik A, et al. A global study of vitamin D status and parathyroid function in postmenopausal women with osteoporosis: baseline data from the multiple outcomes of raloxifene evaluation clinical trial. J Clin Endocrinol Metab. 2001;86(3):1212-1221.

61. Winter W. Bone strength in pure bending: bearing of geometric and material properties. Stud Health Technol Inform. 2008;133:230-237.

62. Ferretti JL, Cointry GR, Capozza RF, Capiglioni R, Chiappe MA. Analysis of biomechanical effects on bone and on the muscle-bone interactions in small animal models. J Musculoskelet Neuronal Interact. 2001;1(3):263-274.

63. Shuid A, Mehat Z, Mohamed N, Muhammad N, Soelaiman IN. Vitamin E exhibits bone anabolic actions in normal male rats. J Bone Miner Metab. 2010;28(2):149-156.

64. Nazrun A, Khairunnur A, Norliza M, Norazlina M, Ima Nirwana S. Effects of palm tocotrienol on oxidative stress and bone strength in ovariectomised rats. Med Health. 2008;3(2):83-90.

65. Cervellati C, Bonaccorsi G, Cremonini E, et al. Oxidative stress and bone resorption interplay as a possible trigger for postmenopausal osteoporosis. Biomed Res Int. 2014;2014:569563.

66. Ibáñez L, Ferrándiz ML, Brines R, Guede D, Cuadrado A, Alcaraz MJ. Effects of Nrf2 deficiency on bone microarchitecture in an experimental model of osteoporosis. Oxid Med Cell Longev. 2014;2014:726590.

67. Yang Y, Su Y, Wang D, et al. Tanshinol attenuates the deleterious effects of oxidative stress on osteoblastic differentiation via Wnt/ FoxO3a signaling. Oxid Med Cell Longev. 2013;2013:351895.

68. Baek KH, Oh KW, Lee WY, et al. Association of oxidative stress with postmenopausal osteoporosis and the effects of hydrogen peroxide on osteoclast formation in human bone marrow cell cultures. Calcif Tissue Int. 2010;87(3):226-235.

69. Maniam S, Mohamed N, Shuid AN, Soelaiman IN. Palm tocotrienol exerted better antioxidant activities in bone than alpha-tocopherol. Basic Clin Pharmacol Toxicol. 2008;103(1):55-60.

70. Abd Manan N, Mohamed N, Shuid AN. Effects of low-dose versus high-dose $\gamma$-tocotrienol on the bone cells exposed to the hydrogen peroxide-induced oxidative stress and apoptosis. Evid Based Complement Alternat Med. 2012;2012:680834.
71. Mo H, Yeganehjoo H, Shah A, Mo WK, Soelaiman IN, Shen CL. Mevalonate-suppressive dietary isoprenoids for bone health. J Nutr Biochem. 2012;23(12):1543-1551.

72. Salman Khan M, Akhtar S, Al-Sagair OA, Arif JM. Protective effect of dietary tocotrienols against infection and inflammation-induced hyperlipidemia: an in vivo and in silico study. Phytother Res. 2011;25(11): 1586-1595.

73. Abdul-Majeed S, Mohamed N, Soelaiman IN. A review on the use of statins and tocotrienols, individually or in combination for the treatment of osteoporosis. Curr Drug Targets. 2013;14(13):1579-1590.

74. Deng L, Ding Y, Peng Y, et al. $\gamma$-Tocotrienol protects against ovariectomyinduced bone loss via mevalonate pathway as HMG-CoA reductase inhibitor. Bone. 2014;67:200-207.

75. Brincat SD, Borg M, Camilleri G, Calleja-Agius J. The role of cytokines in postmenopausal osteoporosis. Minerva Ginecol. 2014;66(4): 391-407.

76. Bruzzaniti A, Baron R. Molecular regulation of osteoclast activity. Rev Endocr Metab Disord. 2006;7(1-2):123-139.

77. Kirkham GR, Cartmell SH. Genes and proteins involved in the regulation of osteogenesis. In: Ashammakhi N, Reis RL, Chiellini E, editors. Topics in Tissue Engineering. Vol 3. 2007. Available from: http://www.oulu.fi/spareparts/ebook_topics_in_t_e_vol3/abstracts/ kirkham_chapter_01.pdf. Accessed March 31, 2015.

78. Abukhadir SS, Mohamed N, Makpol S, Muhammad N. Effects of palm vitamin e on bone-formation-related gene expression in nicotine-treated rats. Evid Based Complement Alternat Med. 2012;2012:656025.

79. Chin KY, Mo H, Soelaiman IN. A review of the possible mechanisms of action of tocotrienol - a potential antiosteoporotic agent. Curr Drug Targets. 2013;14(13):1533-1541.

80. Chin KY, Ima-Nirwana S. The effects of $\alpha$-tocopherol on bone: a double-edged sword? Nutrients. 2014;6(4):1424-1441.

81. Chai SC, Wei CI, Brummel-Smith K, Arjmandi BH. The role of vitamin E in reversing bone loss. Aging Clin Exp Res. 2008;20(6):521-527.

82. Feresin RG, Johnson SA, Elam ML, et al. Effects of vitamin e on bone biomechanical and histomorphometric parameters in ovariectomized rats. J Osteoporos. 2013;2013:1-9.

83. Arjmandi B, Juma S, Beharka A, Bapna MS, Akhter M, Meydani SN. Vitamin E improves bone quality in the aged but not in young adult male mice. J Nutr Biochem. 2002;13(9):543.

84. Smith BJ, Lucas EA, Turner RT, et al. Vitamin E provides protection for bone in mature hindlimb unloaded male rats. Calcif Tissue Int. 2005;76(4):272-279.

85. Fujita K, Iwasaki M, Ochi H, et al. Vitamin E decreases bone mass by stimulating osteoclast fusion. Nat Med. 2012;18:589-594.

86. Iwaniec UT, Turner RT, Smith BJ, et al. Evaluation of long-term vitamin E insufficiency or excess on bone mass, density, and microarchitecture in rodents. Free Radic Biol Med. 2013;65:1209-1214.

87. Mehat MZ, Shuid AN, Mohamed N, Muhammad N, Soelaiman IN. Beneficial effects of vitamin $\mathrm{E}$ isomer supplementation on static and dynamic bone histomorphometry parameters in normal male rats. J Bone Miner Metab. 2010;28(5):503-509.

88. Ima-Nirwana S, Nurshazwani Y, Nazrun AS, Norliza M, Norazlina M. Subacute and subchronic toxicity studies of palm vitamin E in mice. Journal of Pharmacology and Toxicology. 2011;6:166-173.

89. Reagan-Shaw S, Nihal M, Ahmad N. Dose translation from animal to human studies revisited. FASEB J. 2008;22(3):659-661.

90. Nakamura H, Furukawa F, Nishikawa A, et al. Oral toxicity of a tocotrienol preparation in rats. Food Chem Toxicol. 2001;39(8):799-805.

91. Herrera E, Barbas C. Vitamin E: action, metabolism and perspectives. J Physiol Biochem. 2001;57(1):43-56.

92. Stocker A. Molecular mechanisms of vitamin E transport. Ann NY Acad Sci. 2004;1031:44-59. 


\section{Publish your work in this journal}

Drug Design, Development and Therapy is an international, peerreviewed open-access journal that spans the spectrum of drug design and development through to clinical applications. Clinical outcomes, patient safety, and programs for the development and effective, safe, and sustained use of medicines are a feature of the journal, which has also been accepted for indexing on PubMed Central. The manuscript management system is completely online and includes a very quick and fair peer-review system, which is all easy to use. Visit http://www.dovepress.com/testimonials.php to read real quotes from published authors.

Submit your manuscript here: http://www.dovepress.com/drug-design-development-and-therapy-journal 